\title{
LOS OJOS QUE NO LLORAN SE CONFUNDEN ${ }^{1}$
} EYES THAT DON'T CRY GET CONFUSED

\author{
Gemma del Olmo Campillo \\ Universidad de Zaragoza (España)
}

Recibido: 20-05-2012

Aceptado: 26-06-2012

Resumen: En la actualidad persiste un modelo de conocimiento que se presenta como objetivo y riguroso, haciendo caso omiso de las numerosas críticas hechas a esta forma de comprensión que ponen en evidencia el hecho de que el conocimiento universal y objetivo es una ficción, una construcción a la medida de la ambición y la arrogancia humanas. Se trata, claramente, de una fantasía interesada que establece una jerarquía entre los distintos saberes y menosprecia los que se alejan más del ideal de objetividad. Este menosprecio remite a una forma de entender la vida que no respeta la diversidad sino que tiraniza, coloniza, somete o destruye aquello que no valora a través de enfrentamientos incruentos, en la mayor parte de las ocasiones, pero no por ello carentes de violencia.

Palabras-clave: Guerra, violencia, colonización, ficción, conocimiento, soberbia, humildad, razón poética, María Zambrano.

\begin{abstract}
Nowadays a knowledge model is presented as objective and rigorous, ignoring the numerous criticisms of this form of understanding that highlight the fact that the universal and objective knowledge is a fiction, a construction that suits human ambition and arrogance. This is clearly an interested fantasy of establishing a hierarchy between different knowledges and belittles those who are far from the ideal of objectivity. This contempt indicates a way of understanding life that doesn't respect diversity but instead tyrannizes, colonizes, subjugates, or destroys all that it doesn't value through of confrontations that, in most cases, are bloodless, but not devoid of violence.

Key-words: War, violence, colonization, fiction, Knowledge, haugtiness, humilty, poetic reason, María Zambrano.
\end{abstract}

[1] El título es una frase textual de María Zambrano que resume muy bien la intención de la presente aportación. Ver Zambrano, M., El hombre y lo divino, México, Fondo de Cultura Económica, 1993, p. 391. 
A pesar de los numerosos problemas que plantea, persiste en la actualidad de forma generalizada la fe en la existencia de un conocimiento objetivo y riguroso. Es más, en realidad este modelo se presenta como un conocimiento universal y verdadero, el único posible, el que tiene capacidad para lograr importantes descubrimientos y avances tecnológicos: sublime en sus aportaciones e inmejorable en sus resultados. Todo parece posible para el ser humano gracias a su tecnología.

Este modelo de conocimiento apenas se pone en duda porque está avalado por sus espectaculares logros, y ante ellos las críticas pierden fuerza e interés. Los resultados son tan impresionantes que se considera el modelo de conocimiento por excelencia, su superioridad es incuestionable. Es el ejemplo a seguir, es el paradigma de todo saber que tenga pretensiones de seriedad, la guía necesaria para llegar a importantes resultados.

Así pues, se ha concluido que todas las disciplinas que quieran aspirar al rigor, a la seriedad, al respeto de las distintas comunidades de especialistas, deben introducir el método científico y adaptarse a él, implantarlo en sus estudios como un elemento fundamental. De esta forma, se copia un modelo exitoso para tener buenos resultados y no caer en el desprestigiado abismo de la subjetividad. Como corolario de ello, se establece una jerarquía en los saberes, de manera que son más valorados los que están más cerca de la objetividad y de la aplicación más perfecta del modelo de las ciencias empíricas o, diciéndolo de otra manera, todo saber que no alcance logros tangibles que se puedan ponderar y contrastar empíricamente se convierten en saberes sospechosos e inútiles que terminan por ser relegados de la valoración social, económica y científica.

Sin duda, esta concepción ha dañado enormemente a gran parte de las llamadas disciplinas clásicas. Su devastación ha sido implacable. Avalado por sus triunfos, en seguida se erigió como el único conocimiento competente; el endiosamiento del saber empírico y tecnológico ha sido rápido e intransigente. La duda como método pronto fue una perorata más que en modo alguno impidió la vanidad y la insolencia. El desarrollo de sus avances es tal que todo parece posible, la capacidad del ser humano para controlar la naturaleza (y por ello, también a otros seres humanos) se estima infinita.

Desde luego, no pretendo poner en cuestión estos resultados, pues es evidente que se han realizado notables descubrimientos científicos y tecnológicos que han mejorado de forma notable la vida del ser humano. Lo que intento con esta reflexión es pensar sobre los peligros de considerar este conocimiento como el único posible, o de otra forma, los riesgos que conlleva el planteamiento generalizado de presentar el modelo del conocimiento de las ciencias como aquel al que deben de adecuarse otros conocimientos, aduciendo como motivo sus espectaculares avances y resultados. 
Dicha forma de comprensión de la realidad presume de sus logros y se erige a sí misma en saber universal, neutro e imparcial, esto es, dice ser válida para todo el mundo y no incluir ni parcialidades ni exclusiones. La razón de ello es su insistencia en la objetividad, esto es, dice prescindir de las cambiantes emociones y de los molestos sentimientos que pueden llevar al error y la parcialidad.

Tal concepción desde luego llama poderosamente la atención, pero sus éxitos han sido tan deslumbrantes que durante bastante tiempo han logrado ocultar la arrogancia y vanidad que hay en esta manera de percibirse. Lo que en un momento puede parecer un lógico orgullo por lo conseguido, poco a poco se va manifestando como endiosamiento, soberbia y presunción. En este punto las críticas no se hacen esperar, y desde lugares muy diversos.

Sin embargo, con todo, es sorprendente que tras las numerosas argumentaciones que señalan los riesgos de jerarquizar el conocimiento aún se crea que las ciencias más rigurosas son las empíricas y las tecnológicas, y que se siga pensando que es el modelo más adecuado al que deben adaptarse todas las disciplinas. No parece que las críticas hayan permeado porque lo habitual sigue siendo, de forma acrítica y sin fisuras, creer que es posible un conocimiento universal, neutro y objetivo, a pesar de la evidencia de que está elaborado por personas que no lo son, por estudiosos y estudiosas que tienen sus anhelos y deseos, sus intereses y prejuicios. Aún se piensa que es posible una verdad fuera de lo humano, una verdad perfecta y absoluta, válida en todo tiempo y lugar.

No han sido pocas las voces que han criticado esta ficción construida a la medida de grandes expectativas. Parece que cuesta reconocer que somos seres finitos, falibles, parciales, interesados, subjetivos, con prejuicios, etc. Pero lo cierto es que nuestro conocimiento da cuenta de una voluntad ${ }^{2}$, de una subjetividad movida por intereses, deseos y valores, por mucho que lo intentemos ocultar. Por tanto, pretender un conocimiento universal, neutro y objetivo es una ficción que encubre la verdad, de modo que parece más honesto reconocer que todo conocimiento es subjetivo, finito, parcial e interesado, como lo son los seres humanos que lo han elaborado.

Pero hacerlo supone poner en cuestión todo un sistema que no solo jerarquiza disciplinas sino que también establece diferencias de valor, económicas y sociales de quienes se dedican a unos ámbitos u otros. No es tan fácil, por

[2] Nietzsche lo expresó con gran claridad: “LLa moral es la voluntad de poder DE QUIÉN?

Lo que hay de común en la historia de Europa desde SÓCRATES es el intento de hacer que los valores morales dominen sobre todos los otros valores: de manera tal que no sólo sean conductores y jueces de la vida sino también

1. del conocimiento

2. de las artes

3. de las aspiraciones estatales y sociales" (cursivas y mayúsculas del autor).

Nietzsche, F., Fragmentos póstumos (1885-1889), volumen IV, Madrid, Tecnos, 2006, Cuaderno W II 1, otoño de 1887, 9[159], p. 285.

THÉMATA. Revista de Filosofía, $\mathrm{N}^{\circ} 48$ julio-diciembre (2013) pp.: 253-263

doi: 10.12795/themata.2013.i48.23 
lo tanto, como señalar que no es posible ni razonable pensar que hay una sola forma de conocimiento, y proponerse como tal esconde intereses más allá de la mera búsqueda de la verdad. Es bastante intrincado porque supone cuestiones de poder y de prestigio que poco tienen que ver con la ciencia.

Sin embargo, aunque no quería dejar de mencionarlo, no quisiera entrar a analizar este aspecto y me voy a centrar en los peligros de una razón soberbia, en la línea de lo ya dicho por María Zambrano. Es cierto que esta autora se refiere sobre todo a la soberbia de la razón que ha llevado a la filosofía al idealismo ${ }^{3}$, pero creo que este razonamiento es válido también para una forma de conocer que pretende la verdad, la objetividad, la universalidad, ocultando la vida, las personas, e imponiendo esa forma de interpretar como la única rigurosa y seria. Este modo de hacer, en mi opinión, tiene unas consecuencias nefastas.

Con esto, desde luego, insisto en ello, no se pretende renunciar a la razón, ni a lo que la ciencia y la tecnología han conseguido desarrollar, esto sería algo absurdo, sino que lo que aquí se plantea es aceptar la importancia de la sensibilidad, de los afectos, en el conocimiento. Un reconocimiento necesario que nos ayuda a entender mejor los distintos saberes y sus peculiaridades, así como a posicionarnos ante el mundo de una manera más humilde y menos arrogante. Por eso María Zambrano afirma que "los ojos que no lloran se confunden" , porque el corazón es una parte esencial del saber. Es decir, no solo el conocimiento pretendidamente neutro y objetivo es una ficción y una construcción imposible sino que es desafortunado y engañoso ocultarlo. Esta posición refleja una determinada concepción del mundo y unos valores, o de otra manera, la tan buscada objetividad no es más que otra forma de subjetividad, aquella en la que se menosprecia los sentimientos y las pasiones, aquella que considera que hay una verdad ajena a lo humano. La objetividad es el reflejo de una forma de interpretar el conocimiento, que estima unos aspectos en detrimento de otros, es el reflejo de una valoración moral, que enjuicia lo que está bien y lo que está mal, que diferencia la disciplina seria de la que no lo es.

Nos podríamos reír de la incongruencia, del aparente contrasentido, si no fuera por las consecuencias tan desastrosas que ha tenido. El ideal de objetividad tan característico de Occidente ha colonizado y casi destruido otras miradas posibles. Es decir, Occidente no solo ha colonizado territorios, sino que también ha invadido mentes, avasallado lenguas y sometido voluntades. No solo ha menospreciado los tipos de conocimiento que ha catalogado de subjetivos sino que ha convencido a una parte importante de la población mundial para considerar superior la objetividad, y todo lo que aparentemente tenga que ver con ella. La invasión ha sido tan exitosa como lo ha sido su tecnología, in-

[3] Zambrano, M., Pensamiento y poesía en la vida española, Madrid, Endymion, 1987, pp. 23-24.

[4] Zambrano, M., El hombre y lo divino, p. 391.

THÉMATA. Revista de Filosofía, No48 julio-diciembre (2013) pp.: 253-263 doi: 10.12795/themata.2013.i48.23 
cluso más, y ha ejercido una tiranía violenta aunque sin sangre. Ha conseguido gran complicidad para llevar a cabo su propósito, tiene un enorme apoyo social, moral, económico y estatal. El saber objetivo tiene un lugar privilegiado, como lo tuvo para Platón el mundo de las ideas o de las formas. La invasión contó con armas de peso, los adelantos técnicos, y también utilizó armas de destrucción masiva como la falta de reconocimiento y recursos para devastar otros saberes. Se ha propuesto una única forma posible de conocimiento y se ha acabado con la pertinencia y valoración de cualquier otra.

Solo es posible una verdad, la que se llega a través del método científico, o sucedáneos; una única mirada posible, la que somete. Se ensalzan unos tipos de conocimientos y se relegan otros, la jerarquía se establece según la proximidad o lejanía del modelo propuesto por las ciencias. Cuanto más lejos se está del método científico, más desprecio parece merecer. Es una manera de proceder deshonesta y cruel: deshonesta porque esconde la parcialidad de todo conocimiento, cruel porque cosifica a los seres humanos al instrumentalizarlos para que sean valedores de esa moral, de esa ficción, que no por ficción carece de entidad y, por ello, de realidad.

No hay piedad para quienes no estén de acuerdo con la mayoría, para quienes mantengan posturas heterodoxas. Se desoye a las posiciones más minoritarias, convirtiéndolas en débiles. De poco parece haber servido la historia de la ciencia que está llena de ejemplos de descubrimientos científicos iniciados con apenas una intuición, una corazonada, y tampoco se repara en lo que han tenido que pasar muchas de las personas que defendían orientaciones muy distintas a las mayoritarias, y que con el transcurso de los años se han mostrado más efectivas o aclaratorias.

La historia de la ciencia se escribe y reescribe por quienes se consideran en posesión de la verdad, por los vencedores de las pequeñas o grandes batallas de la historia del conocimiento para erigirse en poseedores de la verdad, enfrentamientos incruentos en la mayor parte de las ocasiones pero no por ello carentes de violencia. Se va anulando, poco a poco, aquellas formas heterodoxas de entender el mundo, en lo que podemos llamar una colonización del pensamiento occidental que devasta otras miradas, que daña tiránicamente otras formas de conocimiento.

Es una actitud dogmática que daña las entrañas mismas de los saberes distintos a las ciencias, los daña en su fundamento, en su sentido, en su razón de ser, para abocarlos a una existencia categorial y sistemática que acaba con ellos. Su corazón se paraliza, deja de palpitar, su sentido desaparece junto con el sentimiento que le da vida. "Los ojos que no lloran se confunden" porque construyen una poderosa y atractiva fantasía que anula y destruye lo que no concuerda con su planteamiento, lo que no se puede someter a su mundo ideal.

THÉMATA. Revista de Filosofía, $\mathrm{N}^{\circ} 48$ julio-diciembre (2013) pp.: 253-263 doi: 10.12795/themata.2013.i48.23 
La apuesta de Zambrano de dejar de menospreciar los sentimientos y las pasiones dentro del conocimiento es, creo yo, una salida a la situación actual. Dejar de ocultar que la ciencia se nutre de la vida de sus científicas y científicos, de sus corazones, de sus intereses e intuiciones. Menospreciarlo únicamente lleva a la confusión de construir un mundo ficticio que, paradójicamente, se nos ofrece como más verdadero y real que aquel en el que vivimos. Los ojos que no sienten, señala María Zambrano ${ }^{5}$, son aquellos que se quedan fijos en el ver, puro cristal sin sentimiento que ya no llora porque se sigue creyendo que los ojos solo sirven para ver, que ya no parpadea por el miedo a la oscuridad. Una mirada pobre, seca, interesada y adiestrada, originada por una moral pobre, seca, interesada y disciplinaria que construye un ente ficticio sin sensibilidad ni entrañas. Un edificio erigido bajo la máxima de la deshumanización, aunque haya sido hecho por seres humanos, parece que así la confianza, el rigor, la veracidad, se nos antoja mayor.

Zambrano señala que hay una rebelión de la vida ${ }^{6}$. Esta imposición no puede prosperar sin una resistencia, hay una respuesta ante la soberbia de la razón. Pero, advierte, la idea no es que la vida se ensoberbezca también, para ella la mediación entre razón y vida es justo el inicio de una nueva posibilidad. El pensamiento auroral que integre la razón y el corazón, haciendo imposible la construcción de mundos alejados de la vida, ficticios, deshumanizados. Zambrano, en su crítica a la razón, no tiene la pretensión de abolirla, no quiere hacer la misma iniquidad, lo que pretende es mediar, unificar, reconciliar de forma honesta los distintos aspectos que componen lo humano.

Las formas del saber no deben imponerse, han de ser descubiertas, y para ello es necesaria una predisposición muy distinta a la habitual, que no fuerce al objeto, que no invada, que no tiranice. Una actitud pasiva que deje ser a lo otro mediante una escucha activa. Para esta autora, todo descubridor tiene dos virtudes: la audacia y la humildad ${ }^{7}$. La audacia que permita atreverse a todo, sin olvidar por ello las propias limitaciones, y la humildad intelectual necesaria para dejar que las cosas se expresen con libertad, sin dogmatismos ni imposiciones. Para María Zambrano la humildad intelectual es indispensable en toda reflexión porque el orgullo ha sido el causante de que la razón se vuelva violenta, de que se haya forzado la realidad para adaptarla a los distintos sistemas. La forma de entender lo que nos rodea presupone también una manera de entender la vida, no es algo separado, está en la persona en la subjetividad inherente a cada persona y de la que no es posible escapar. Decir que se hace, es una valoración más, una forma de subjetividad más.

[5] Ibídem.

[6] Zambrano, M., Pensamiento y poesía en la vida española, p. 23.

[7] Ibídem, p. 24.

THÉMATA. Revista de Filosofía, Nº $^{\circ} 8$ julio-diciembre (2013) pp.: 253-263 doi: 10.12795/themata.2013.i48.23 
María Zambrano cree que es posible una forma de vivir y de pensar más honesta y humana. Para ello es preciso mediar entre la razón y el corazón, la luz y la oscuridad, la reflexión y la vida. Mediar porque no son pares de contrarios, sino distintas actitudes presentes en una sola persona. Desatender una u otra es una pérdida, la necesidad de mediación es lo que Zambrano señaló con su razón poética. La razón se integra con la poesía porque "la razón sola no acierta”, necesita la pasión, pero que la pasión sola tampoco es autosuficiente porque "ahuyenta la verdad". El ser humano no se encuentra entero en la razón, y tampoco está la totalidad de lo humano en la poesía ${ }^{9}$. Es preciso integrar la razón y la pasión: el anhelo de luz que se complementa con la oscura cavidad del corazón, con el misterio siempre anhelante de desvelarse.

La exclusión es siempre una pérdida, el exilio es una deuda irrestituible. Ni la exclusión ni el exilio son dos posibilidades adecuadas para Zambrano, y su razón poética es, precisamente, el método para conciliar ámbitos supuestamente incompatibles. Digo supuestamente porque no lo son, no son incompatibles, no pueden serlo, pueden ser paradójicos o estar en tensión permanente, pero no incompatibles porque si forman parte de la vida humana conviven de una forma u otra. No son polos contradictorios sino que requieren mediación. Así ocurre, por ejemplo, con la razón y con la poesía, que ella aúna en su razón poética. No son elementos irreconciliables, antes bien, necesitan la reconciliación, el encuentro, para que nazca un nuevo conocimiento, solo en su encuentro será posible un nuevo inicio que acabe con lo anterior. El nuevo conocimiento será aquel que logre conciliar la búsqueda de la razón, que inquiere constantemente, con la poesía, que encuentra ${ }^{10}$. El nacimiento esperanzado de otra forma de interpretar el mundo que no se base en la exclusión, la jerarquización y la violencia, sino en el pensamiento libre, disperso, que no anhele la totalidad ni lo absoluto, un pensamiento que no enclaustre bajo la forma de sistemas ${ }^{11}$, sino que busque otras cosas, que nazca de la admiración y que no se asuste del cambio, de la ambigüedad, de los sentimientos.

Este nuevo nacimiento, por otra parte, es posible porque la invasión no ha sido completa, la destrucción no se ha consumado, quizá no pueda hacerse del todo, no se puede ocultar en su totalidad algo tan fundamental de lo humano como son las emociones y los sentimientos, la subjetividad y la opinión. La vida, como se ha comentado unas líneas más arriba, se ha rebelado. En los márgenes, en los límites hay resistentes, personas que han sufrido las consecuencias de las tiranías, que se saben tiranizadas y que apuestan por un conocimiento distinto, sin imposiciones, sin dogmas, que no pretenden la uni-

[8] Zambrano, M., Hacia un saber sobre el alma, Madrid, Alianza, 1993, p. 19.

[9] Zambrano, M., Filosofía y poesía, México, Fondo de Cultura Económica, 1996, p. 13.

[10] Ibídem.

[11] Zambrano, M., Pensamiento y poesía en la vida española, p. 31.

THÉMATA. Revista de Filosofía, № 48 julio-diciembre (2013) pp.: 253-263 doi: 10.12795/themata.2013.i48.23 
versalidad, sino que aprecian la diversidad y la falta de certezas, que aprecian, en definitiva, la honestidad intelectual.

Algo tan nimio como esto, tan aparentemente insignificante, puede ser una verdadera resistencia al poder y los dogmatismos, a las imposiciones morales e ideológicas, a los sistemas totalitarios, a las tiranías del bien y de la verdad. Son resistencias que retan al poder y a las normas impuestas por los "comités de sabios" que se convierten en auténticos tiranos. Hay una verdadera rebeldía en quienes apuestan por las emociones y no se avergüenzan de ellas, pues forman parte de lo humano. Las emociones no llevan al error sino a estar más cerca de la verdad.

La alegría, el dolor, las filias y las fobias pueden convertirse en lugares de resistencia ante el ideal deshumanizado de objetividad, espacios en los que reconocer y reconocernos, donde asumir que las emociones forman parte de lo que somos y de lo que hacemos y no son algo que hay que esconder. Ocultarlo supone ya, en cierto modo, mentir. Y no solo eso, también supone una pérdida porque esas emociones muestran una parte de la verdad, o mejor, que la verdad también habita en los sentimientos.

En este sentido, puede decirse que el personaje de Antígona es una de estas figuras de resistencia, se mantuvo firme y con determinación llevó a cabo lo que consideraba su obligación, algo que, a su pesar y sin pretenderlo, le enfrentó al poder de su tío, el rey Creonte. El rey quería castigar a Antígona por haber incumplido su edicto, no quería ser considerado débil y no mostró ninguna benevolencia hacia Antígona: debía ser escarmentada porque sus leyes, para que sean tales y pueda continuar en el poder, tienen que ser cumplidas. La obediencia ciega se premia con la vida; la insubordinación justificada y sensata se castiga duramente, con la muerte en este caso. No hay espacio para detenerse a pensar las situaciones concretas, ni en la justicia que puede haber en determinados actos, o en la posible necesidad de ir contra las normas para poder vivir, para poder ser quien se es, sin pretender hacer daño a nadie ni siquiera iniciar una revolución. Este es el caso de Antígona.

Antígona es condenada a muerte, pero no muere como consecuencia directa de las órdenes del rey, pues ella se suicida antes de que se ejecute la pena y antes de que llegue el rey para indultarla, arrepentido por dejarse llevar por la soberbia. Sin embargo, María Zambrano se da cuenta de la importancia de la voz de Antígona, de que hablara allí donde tenía más sentido que lo hiciera, en su tumba: "ni en la vida ni en la muerte"12, ni "con los vivos ni con los muertos"13. Y así tituló su obra: La tumba de Antígona.

[12] "Antígona, enterrada viva, no morirás, seguirás así, ni en la vida ni en la muerte, ni en la vida ni en la muerte..." Zambrano, M., Senderos. Los intelectuales en el drama de España. La tumba de Antígona, Barcelona, Anthropos, 1989, p. 224.

[13] “¡Ay de mí, desdichada, que no pertenezco a los mortales ni soy una más entre los difuntos, que ni estoy con los vivos ni con los muertos!" Sófocles, Tragedias. Áyax, Las Tranquilias, Antígona,

THÉMATA. Revista de Filosofía, No48 julio-diciembre (2013) pp.: 253-263 doi: 10.12795/themata.2013.i48.23 
De esta manera, Zambrano reelaboró la tragedia de Sófocles y a través de Antígona quiso dar voz a las víctimas sacrificadas en nombre de las ideas e ideologías ${ }^{14}$. Para Zambrano, la voz de Antígona, su resistencia, su exilio, su destierro, será revivido tantas veces como se imponga la exclusión y la falta de piedad. La voz de quienes están en una posición débil que, sorprendentemente, pueden llegar a derrocar un gobierno. La piedad, el trato humano, el amor, puede llegar a derrocar un gobierno, como ocurrió en la tragedia de Antígona. En la debilidad de Antígona estaba su fortaleza y en la fortaleza del rey estaba su debilidad. La soberbia lleva a la ceguera, a la falta de conmiseración, a pensar que somos superiores y que todo está a nuestro alcance, pero no es así.

Antígona se sacrifica, afirma Zambrano, para que haya un nuevo comienzo, el de la conciencia ${ }^{15}$, una conciencia piadosa que no invente ideales, que no pida sacrificios en nombre de las ideologías, que no excluya ni menosprecie. Que trate con humanidad a lo otro ${ }^{16}$.

Esta es la manera de dejar atrás también las formas de pensamiento totalitarias, tiránicas, que deciden lo que es verdad y lo que no atendiendo al método utilizado que, además, se proponen como las formas válidas para todo saber que aspire a ser un conocimiento riguroso y serio. Seguir como hasta ahora supone exiliar las disciplinas que no aspiran a la objetividad, desplazarlas hacia espacios menospreciados, aduciendo que son disciplinas subjetivas. Es hora de cambiar esta situación, de pensar, reflexionar, detener este totalitarismo y hegemonía de unas disciplinas sobre otras que imponen su forma de hacer como la única posible.

Es hora de detener esta colonización. Pensar es la única herramienta que tenemos a mano. Reflexionar sobre lo que hacemos, sobre lo que pedimos, lo que consideramos valioso. Meditar sus consecuencias, las exclusiones que suponen, las dificultades que imponen a otras formas de interpretar el conocimiento. Tener todo esto muy en cuenta es la única forma de enfrentarse a los estragos de un pensamiento totalitario.

Hannah Arendt denuncia que los totalitarismos no solo suponen una coacción exterior, sino que también suponen una colonización interior que asume las ideas de forma acrítica, sin reflexión ninguna, bajo la forma de obediencia al mandato ${ }^{17}$ que no es pasiva, sino que incluye la sospecha mutua y la delación, lo cual provoca rivalidades y competencia para sobresalir ${ }^{18}$, así como

Edipo Rey, Electra, Filoctetes, Edipo en Colono, Madrid, Gredos, p. 281.

[14] Zambrano, M., Senderos. Los intelectuales en el drama de España. La tumba de Antígona, p. 221.

[15] Ibídem, 218. Ver también Zambrano, M., El hombre y lo divino, p. 62.

[16] Zambrano, M., El hombre y lo divino, p. 207.

[17] Arendt, H., La condición humana, Barcelona, Paidós, 1998, p. 245.

[18] Arendt, H., Los orígenes del totalitarismo. 3. Totalitarismo. Madrid, Alianza, 1987, p. 643.

THÉMATA. Revista de Filosofía, $\mathrm{N}^{\circ} 48$ julio-diciembre (2013) pp.: 253-263 doi: 10.12795/themata.2013.i48.23 
la autocoacción, que consiste en aceptar como verdadera la lógica de las ideas, explicaciones y justificaciones del sistema totalitario ${ }^{19}$, de manera que se construye una verdad incuestionable carente de contradicciones o de excepciones.

Pero, como en el caso de María Zambrano, Hannah Arendt también da espacio a la esperanza, siempre es posible un nuevo inicio, alguna acción que puede transformar de forma radical la convivencia y la forma de interpretar la realidad. De modo que la posibilidad de salir de los totalitarismos y de las tiranías está siempre abierta porque, además, señala Arendt, estos incluyen en sí mismos los gérmenes de su destrucción ${ }^{20}$.

La posibilidad de un nuevo inicio ${ }^{21}$ es una esperanza real y factible, solo hay que pensar en lo que es preciso cambiar, y evitar todo aquello que anule la acción libre. De esta manera siempre existirá la esperanza de que en nuestras manos está poder construir lugares más habitables.

[19] Ibídem, p. 695.

[20] Ibídem, p. 706.

[21] Arendt, H., La condición humana, p. 227.

THÉMATA. Revista de Filosofía, Nº48 julio-diciembre (2013) pp.: 253-263 doi: 10.12795/themata.2013.i48.23 


\section{BIBLIOGRAFÍA}

Arendt, Hannah, La condición humana, Barcelona, Paidós, 1998.

—, Los orígenes del totalitarismo. 3. Totalitarismo. Madrid, Alianza, 1987.

Bundgård, Ana, Más allá de la filosofía. Sobre el pensamiento místico de María Zambrano, Madrid, Trotta, 2000.

-, (2009), Un compromiso apasionado. María Zambrano: una intelectual al servicio del pueblo (1928-1939), Madrid, Trotta.

Nietzsche, F., Fragmentos póstumos (1885-1889), volumen IV, Madrid, Tecnos, 2006.

Ortega, Juan Fernando (ed), María Zambrano. La aventura de ser mujer, Málaga, Veramar, 2007.

Gómez, Mercedes, La razón mediadora. Filosofía y Piedad en María Zambrano, Burgos, Editorial Gran Vía, 2008.

Rivera, María-Milagros (trascripción), «Entrevista a María Zambrano (19041991), a cargo de Pilar Trenas, emitida en el programa "Muy personal" de Televisión Española (1988)», Duoda. Revista de estudios feministas, 25, 2003, pp. 141-165.

Sánchez-Gey, Juana, "Sobre la mujer: experiencia y reflexión en María Zambrano», El Basilisco, 21, 1996, pp. 76-78.

Santamaría, Ana Laura, Implicaciones éticas de la Antígona de Sófocles. Una reflexión sobre el pensamiento trágico griego, México, Plaza y Valdés, 2009.

Sófocles, Tragedias. Áyax, Las Tranquilias, Antígona, Edipo Rey, Electra, Filoctetes, Edipo en Colono, Madrid, Gredos, 1986.

Steiner, George, Antígonas. Una poética y una filosofía de la lectura, Barcelona, Gedisa, 1987.

Tommasi, Wanda, María Zambrano. La passione della figlia, Nápoles, Liguori, 2007.

Zamboni, Chiara (ed.), María Zambrano, in fedeltà alla parola vivente, Florencia, Alinea, 2002.

Zambrano, María, Pensamiento y poesía en la vida española, Madrid, Endymion, 1987.

—, Senderos. Los intelectuales en el drama de España. La tumba de Antígona, Barcelona, Anthropos, 1989.

—, El hombre y lo divino, Madrid, Fondo de Cultura Económica, 1993.

-, Hacia un saber sobre el alma, Madrid, Alianza, 1993.

—, Filosofía y poesía, Madrid, Fondo de Cultura Económica, 1996. 